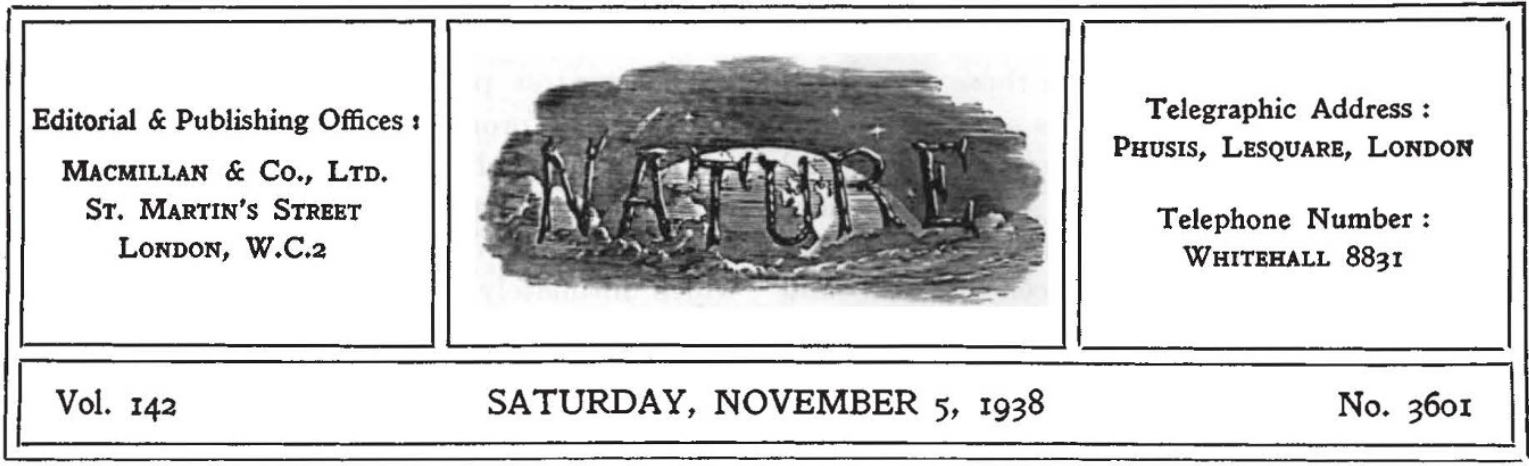

\title{
Science in World Affairs
}

$\mathrm{I}^{\mathrm{N}}$ recent broadcast addresses, Mr. Neville Chamberlain and President Roosevelt have pleaded for peace among civilized peoples by consultation instead of force-whether displayed to produce fear or actually used to oppress or subjugate races or nationalities. In the speech which the Prime Minister broadcast at the darkest hour of the recent crisis, he affirmed his conviction that any nation which attempted to dominate the world by fear of its force should be resisted, and that under such a domination the life of people who believe in liberty would not be worth living. President Roosevelt stated very clearly the basic principles of permanent peace by which alone can we hope for scientific or any other quality of human progress. "There can be no peace," he said, "if the reign of law is to be replaced by a recurrent sanctification of sheer force. There can be no peace if national policy adopts as a deliberate instrument the dispersion all over the world of millions of helpless, persecuted wanderers with no place to lay their heads. There can be no peace if men and women are not free to think their own thoughts, to express their own feelings, and to worship God. There can be no peace if economic resources which should be devoted to economic reconstruction are to be diverted to intensified competition in armaments-to a competition which will merely heighten suspicions and fears and threaten the economic prosperity of each and every nation."

It is obvious that the spirit of this declaration is opposed to the urge of nationalism which is now the chief cause of conflicting policies. Any nation which separates itself from the rest of the world in the name of race or religion, and cultivates ideals of conquest by force in order to impose its beliefs upon others, is not promoting social or ethical evolution but retarding it. Science has made the world a single unit through the facilities of communication and transport now available, and it recognizes no political or racial boundaries in its fields of knowledge. To limit study or research in science to any national or racial group, and to disregard other contributions to the progress of natural knowledge, is to betray all that is best in scientific intention. Among modern and social intellectual forces, science alone speaks in a tongue which meets with universal understanding: if it should ever consent to be coerced into a purely nationalistic policy its suicide is inevitable.

What is wanted to-day is the international spirit of science in the consideration of problems in which the interests of several nations are involved. This, as is suggested in a letter signed by the Archbishop of York, the Bishop of Bristol, Sir Gowland Hopkins, Sir Thomas Holland, Sir Frederic Kenyon, Sir Richard Gregory, Mr. H. G. Wells, and others, published in The T'imes of October 29, is the kind of moral rearmament to which attention should be given by all statesmen if rationalism instead of nationalism is to be an effective power in shaping the destiny of mankind. The plea made in the letter is for a World Foundation such as has been initiated in the United States by Señor de Madariaga with a two-fold purpose : (1) to foster the idea of world unity among all peoples, and (2) to promote inquiries directed towards political and economic appeasement on all fronts. These two purposes are essentially complementary. Only through a new conception of world unity can we override the rock of national bias upon which so many admirable international schemes split.

In the development of the social instinct, a sense 
of consideration for the needs of others has grown from the primitive stage in which it embraced members of the blood kin only, or those of the local group within which the members are more or less intimately acquainted, to national groups, and to a commonwealth of nations. A World Foundation would embrace all to whom the dignity of man as an individual entity transcends racial and political boundaries. When such a world commonwealth extends to all men of good will, it will be possible to estimate how far the human race has advanced along the road of spiritual as well as material progress. The urge of nationalism and its ideals has diverted the thoughts of peoples in totalitarian States away from the main stream of human progress into narrower channels in which rocks and rapids threaten at every turn to shipwreck all that is best in civilization.

The efforts which scientific workers of any nationality may be expected to make in response to calls for unity and service should have for their ultimate aims a world federation and the preservation of intellectual freedom. Preparations for war, whether limited to the organization of national defence or not, cannot suffice in themselves to meet this present challenge of our day to all that is best in the heritage of mankind. The call which Dr. E. C. Conklin addressed to the American Association for the Advancement of Science last December, that those who inherit the tradition of liberty of thought, speech and Press, and believe that it is essential to all progress, should use their utmost influence to see that intellectual freedom shall not perish from the earth, has but gained in cogency from events that have since taken place.

Such freedom is still essential for the advance of science, and scientific workers to-day may well feel even more than a year ago that the time has come when science should stand openly for freedom, especially in countries where force, war and civil disabilities leading to exile are used to compel acceptance of political or social creeds. The growing restriction of intellectual liberty is, indeed, the most disturbing feature of the present international situation. From many sources before and as well as after the recent crisis have come appeals to rally in defence of liberty, and scientific workers have more rather than less reason than the ordinary citizen to respond to that appeal. Science is everywhere the same in aims and methods. Its advance has depended on the contributions of individual inquirers without distinction of race, and anything that limits their contribution or hinders the exchange of views or the contact between different workers impedes that advance.

The greatest problems that confront mankind to-day-the promotion of social co-operation, justice and brotherhood, the upholding and development of loyalty to truth, and the expansion of ethies until it embraces all mankind, are problems which intimately concern science, which indeed must bring its own contribution to their solution. There is, however, an even greater challenge. Such problems can only be solved if we zealously guard the freedom and integrity of our thought, boldly facing new conditions and meeting every problem without shrinking from difficulties, but faithful to the laws which govern our intellectual being.

It is precisely because, when freedom of thought and work in scientific research and investigation are threatened their integrity is threatened also, that the question is of such vital importance to science to-day. Unless the present contraction of liberty is checked, the threat to the advance of science and all that it implies for mankind will grow more serious. Already the free intercourse of men of science has been seriously checked, both directly and indirectly through the doubts thrown on the integrity of what purports to be scientific work in certain totalitarian States. Even in the remaining democracies the orientation of scientific work is liable to be changed and restrictions imposed, if more insidiously, on the full freedom of scientific work, through the exigencies of national defence.

With this position no scientific worker who cares seriously for the integrity of his work or the advancement of his science can rest content. Alike in the prosection of the research directly concerned with matters of national defence, as for example, in the distribution of population or building, or in the obiective study of social problems and international relations, which are a fundamental part of any policy directed to prevent or eliminate war, the principle of intellectual freedom is a vital condition. Violation of this principle injures the whole quality of the scientific contribution and may ultimately destroy it, while at the same time it hinders the wholehearted co-operation of all scientific workers which is so essential alike in the organization of national defence or a policy for peace.

The defence of intellectual freedom is thus a matter of immediate practical importance to the scientific worker, whether from the point of view of the integrity of his particular science or his response to the call for national service. He must 
neglect no opportunity, either as a citizen or as a professional man, of urging support for a policy which fully safeguards such freedom and be prepared to co-operate with any national movement which aims at ensuring this essential principle of progress. He should also be prepared to accept his share in the task of rehabilitating the many men of learning whose work has been interrupted by violation of this principle in other countries. Equally he should be prepared to take his part in the clear thinking required to formulate sound principles of relations between the scientific profession and the State, and to accept loyally the discipline or code of ethics thus evolved. Nor must he fail to uphold the principle of supreme loyalty to truth, essential no less in the smallest scientific investigation than in the broad programmes of objective research into social and international problems which must be pursued if we are to build a world order from which the fear of war and the wastage of armaments is ultimately banished.

\section{Seasonal Periodicity of Malaria}

The Seasonal Periodicity of Malaria and the Mechanism of the Epidemic Wave

By Dr. Clifford Allchin Gill. Pp. xi +136. (London: J. and A. Churchill, Ltd., 1938.) 10s. $6 d$.

THE discovery by Ross of the mosquito cycle made it possible for the first time to explain a host of facts in the epidemiology of malaria which otherwise were entirely inexplicable. It very soon became evident that malaria, instead of being contracted from man's general surround. ings in Nature, as up to then had been supposed, was merely a special case of a man-to-man infectious disease, differing only from other infectious diseases in that an intermediate insect host was required for its transmission. That the insect host was a necessary factor did not at first presuppose any very complicated relationship in this respect. If there was no vector there would naturally be no malaria; but other things being equal, the amount of malaria might be expected to be in proportion to the numerical prevalence of the incriminated insect.

This relatively simple outlook was soon found, however, to be far from an adequate one, and the history of malaria investigation has more and more shown how complex are the factors which determine malaria prevalence. Especially have recent researches shed unexpected new light in this field. In the book under notice, Colonel C. A. Gill gives a very clear and readable exposition of some of these new additions to knowledge. Malaria does not merely show different degrees of prevalence in different regions of the earth; it exhibits also peculiarities in the different terrestrial zones which can be described and defined.

It is one of the merits of this small volume that it has for the first time clearly and interestingly given both the limits and the reasons for the existence of these zones. The zones are essentially related to temperature and humidity, the different combinations and permutations of which, acting through the insect vector, the human host and the parasite, bring about special features which characterize each zone. Thus below a certain critical summer temperature, Plasmodium falciparum fails to make good and the field is occupied, to the virtual exclusion of other forms of the parasite, by Plasmodium vivax. The long-term relapse which is characteristic of this parasite not only appears to have enabled it to circumvent what would otherwise be very serious difficulties in maintaining transmission, but it also gives to malaria in the temperate malaria zone quite peculiar seasonal and other epidemiological features.

Subtropical zone malaria and tropical zone malaria differ from each other largely because, in the latter, long periods of extremely low humidity lead to decreased human immunity, so that this zone is apt to be the site of those vast epidemics which hitherto in northern India have, literally, controlled the population. These epidemics follow abnormally heavy rainfall and are terminated by the onset of a cold season. Equatorial zone malaria has its own form of epidemic which, as in the recent Ceylon epidemic, follows upon drought and not upon heavy rainfall, and possesses features due to the fact that there is no cold season to cut short its course.

All these interesting differences are very clearly set out by Colonel Gill who, proceeding from the normal to the abnormal, has been in the position to make a very valuable contribution to our knowledge of the causes and mechanism of epidemics of malaria. The book is one which all malariologists should read. 